\title{
Identifikasi Interaksi Ekonomi Sektoral Antara Kota Mataram Sebagai Pusat Pertumbuhan Ekonomi dengan Kabupaten yang Ada di Pulau Lombok Provinsi Nusa Tenggara Barat
}

\author{
Muhammad Alwi*, Putu Karismawan, dan Ade Paranata \\ Fakultas Ekonomi dan Bisnis Universitas Mataram \\ *Corresponding Email: muhnurrahmah303@gmail.com
}

\begin{abstract}
Info Artikel
Kata Kunci:

Interaksi sosial ekonomi

Tujuan penelitian ini adalah untuk mengetahui sektor: Unggulan, prospektif, andalan dan sektor tertinggal pada setiap Kabupaten dan kota di Pulau Lombok. Tujuan lainnya adalah Kabupaten yang mana mempunyai interaksi yang kuat dengan Kota Mataram sebagai pusat pertumbuhan. Metode analisis yang digunakan adalah metode sintesis analisis SLQ dan DLQ dan meode Gravitasi. Data yang digunakan dalam analisis ini adalah data PDRB, Jumlah Penduduk setiap Kabupaten dan Kota di Pulau Lombok serta jarak setiap Kabuputen dengan Kota Mataram. Hasil penelitian menunjukan bahwa; Kota Mataram unggul hampir di semua sektor sekunder dan tersier, yaitu ada sebanyak 12 sektor unggulan, satu sector andalan dan dua sektor prospektif.Kabupaten Lombok Utara (KLU) sebagai Kabupaten termuda menunjukkan progresifitas yang menonjol, dengan delapan sektor unggulan, satu sektor andalan dan delapan sektor prospektif.Ada beberapa sektor unggulan di setiap Kabupaten/Kota yang sama, seperti sektor 6 (sektor Konstruksi) terklasifikasi sebagai sektor unggulan di empat kabupaten, kecuali Lombok Tengah. Ini dapat dijadikan indikasi adanya keterkaitan antar sektor dan antar wilayah yang saling memperkuat pengembangan sektor tersebut di setiap wilayah. Kota Mataram sebagai pusat pertumbuhan, dalam pengembangan sektor konstruksi disangga oleh Kabupaten lain, dalam hal penyediaan bahan galian, sementara untuk keperluan bahan-bahan konstruksi hasil industri, seperti semen, besi, dll, disediakan oleh Kota Mataram Selanjutnya interaksi yang kuat dengan kota Mataram sebagai pusat pertumbuhan ekonomi adalah selama tahun 2013-2014 adalah Kabupaten Lombok Barat dimana Kabupaten mempunyai jarak yang terdekat dengan kota mataram yang ditunjang oleh jumlah penduduk yang dan tingkat pendapatan perkapita yang yang tinggi . Pada tahun 2016-2017 posisi interaksi ekonomi yang terkuat beralih ke Kabupaten Lombok Tengah yang ditunjang oleh lancarnya tramsportasi dari Mataram ke Bandara Internasional Lombok (BIL), di samping itu PDRP/Kapita telah meningkat tajam sampai lebih $3 \times$ lipat dari tahun 2013. Sedangkan interaksi ekonomi yang terendah adalah sejak tahun 2013 - 2017 adalah Kabupaten Lombok Utara (KLU). Hal ini sebabkan karena Kabupaten ini merupakan Kabupaten yang termudah di Pulau Lombok dengan tingkat pendapatan perkapita dan jumlah penduduk yang rendah.
\end{abstract}

\section{ABSTRACT}




\section{Elastisitas - Jurnal Ekonomi Pembangunan \\ Vol. 2 No. 1, Maret 2020}

\section{PENDAHULUAN}

Kota mataram merupakan ibu kota Provinsi Nusa Tenggara Barat yang berada di Pulau Lombok. Sebagai ibu kota Provinsi dan pusat pertumbuhan menyebabkan kota ini berkemabang pesat dari berbagai bidang, seperti bidang perdagangan, bidang pariwisata, dan bidang jasa lainnya. Perkembangan ini tidak terlepas dari fungsi kota mataram sebagai pusat perdagangan, pusat pendidikan, pusat lembaga keuangan dan pusat jasa lainnya. Di samping tersebut, perkembangan dan pertumbuhan ekonomi tidak terlepas dari potensipotensi yang ada diwilayah sekitarnya terutama wilayah yang ada di pulau Lombok. Adapun wilayah tersebut adalah Kabupaten:
a. Kabupaten Lombok Barat
b. Kabupaten Lombok Tengah
c. Kabuten Lombok Timur
d. Kabupaten Lombok Utara

Biasanya hasil produksi dari yang potensial seperti hasil pertanian biasanya juga di pasarkan dikota Mataram melalui pedagang pengumpul atau pemasarkan sendiri sebaliknya kebutuhan sekunder dan jasa lainnya biasanya penduduk daerah sekitarnya membeli di Kota mataram baik untuk kebutuhan perdagangan maupun kebutuhan akan konsumsi.Keterkaitan antara suatu daerah dengan daerah lainnya merupakan hal sangat penting diperhatikan, keterkaitan yang erat dapat menunjukkan keeratan hubungan dalam menunjang pertumbuhan ekonomi masing-masing daerah.Adapun tujuan Penelitian adalah untuk mengetahui sector unggulan, sector prospektif, sector andalan, dan sector tertinggal masing-masing Kabupaten/Kota di Pulau Lombok dan untuk menganalisis keterkaitan ekonomi sektoral antarKota Mataram sebagai pusat pertumbuhan ekonomi dengan Kabupaten yang ada di Pulau Lombok

\section{TINJAUAN PUSTAKA}

Konsep Pusat pertumbuhan ini dapat dijelaskan dengan dua cara yaitu konsep pusat pertumbuhan secara fungsional dan secara geografis. Secara fungsional, pusat pertumbuhan dapat dijelaskan sebagai suatu lokasi konsentrasi kelompok usaha atau cabang industri yang karena sifat hubungannya memiliki unsur-unsur kedinamisan sehingga mampu menstimulasi kehidupan ekonomi baik ke dalam maupun keluar (daerah belakangnya). Secara geografis, pusat pertumbuhan adalah suatu lokasi yang banyak memiliki fasilitas dan kemudahan sehingga menjadi pusat daya tarik (pole of attraction), yang menyebabkan berbagai macam usaha tertarik untuk melakukan kegiatan ekonomi di tempat tersebut dan masyarakat senang datang untuk memanfaatkan fasilitas yang ada di kota tersebut, walaupun kemungkinan tidak ada interaksi antara usaha-usaha tersebut (Tarigan, 2005: 162-163).

Pertumbuhan Kota tergantung pada spesialisasinya dalam menjalankan fungsi pokok suatu pusat Kota sebagai Pusat Pelayanan bagi daerah-daerah belakangnya. Fungsi pokok ini terjadi karena daerah tersebut mengemban fungsi sosial-ekonomi yang bertindak untuk melayani daerah hinterland-nya (desa atau Kota lainnya yang mempunyai pengaruh hubungan yang kuat). Kota yang mampu melayani masyarakat Kota sering disebut fungsi kota, yang selalu dikaitkan dengan sosial-ekonomi utama suatu kota.

Fungsi Kota dicerminkan oleh kelengkapan dan kualitas fasilitas pelayanan perkotaan yang dimilikinya, disamping itu kota ditinjau dari segi aksesibilitasnya ke kota-kota lain atau wilayah belakangnya. Pola ideal yang diharapkan terbentuk, asumsi homogen dalam hal bentuk Medan, kualitas tanah dan tingkat ekonomi penduduk serta budayanya, Christaller menyajikan bentuk pola pelayanan seperti jejaring segi enam (hexagonal). Bentuk pola pelayanan hexagonal ini secara teoritis mampu memperoleh optimasi dalam hal efisiensi transportasi, pemasaran dan administrasi Haggett (2001), dalam Pebrina (2005: 55).

Kota sebagai pusat pelayanan, juga diharapkan memiliki fasilitas pelayanan seperti; (1) pusat dan pertokoan sebagai focus point dari suatu kota, (2) sarana dan prasarana transportasi, (3) tempat rekreasi dan olahraga, dan 


\section{Elastisitas - Jurnal Ekonomi Pembangunan \\ Vol. 2 No. 1, Maret 2020}

(4) sarana pendidikan, kesehatan dan obyek wisata. Dengan demikian kota menyediakan segala fasilitas bagi kehidupan baik sosial maupun ekonomi bagi penduduknya, sehingga baik tempat tinggal maupun bekerja dan berkreasi dapat dilakukan dalam kota (Jayadinata, 1992 : 104).

Fasilitas-fasilitas tersebut merupakan sarana untuk memenuhi kebutuhan kebutuhan penduduk. Semakin lengkap penyediaan fasilitas-fasilitas di suatu tempat berarti semakin kuat daya tarik mengundang penduduk dan kegiatan-kegiatan produktif untuk datang ke tempat tersebut.Dalam meningkatkan pembangunan wilayah harus diupayakan untuk memanfaatkan peran kota-kota sebagai pusat pertumbuhan dan pusat pelayanan. Ada dua faktor penting perlu diperhatikan sehubungan dengan peran pusat-pusat dan hierarki dari masing-masing pusat (Soegijoko, 1995: 78).

Daerah perkotaan sebagai pusat pertumbuhan wilayah akan berfungsi sebagai pusat anglomerasi ekonomi yang mendorong timbulnya kekuatan ke depan dan ke belakang antara titik pusat dan daerah belakangnya dalam menjaga kelangsungan hidup penduduk dan kegiatan fungsional wilayah atau daerah. Gilbert (1975) dalam Adisasmita (1994: 99101), pusat-pusat pelayanan yang lebih kecil adalah penghubung antara pusat-pusat pelayanan yang lebih besar dengan daerah pedesaan. Hubungan.pengembangan pusatpusat pelayanan dalam strategi perencanaan pembangunan regional bukan hanya diarahkan untuk meningkatkan pendapatan riil penduduk, akan tetapi juga untuk menghilangkan atau mengurangi ketimpangan antara daerah perkotaan dan daerah pedesaan. Sejalan dengan tujuan pembangunan wilayah, maka penyediaan fasilitas pelayanan dasar perkotaan sebagai salah satu bentuk pelayanan untuk meningkatkan kesejahteraan masyarakat kota, seharusnya adalah diusahakan untuk memenuhi tiga buah prinsip yaitu affordability, recoverability dan replicability Prakash (1985), dalam Pebrina (2005: 55).

Uraian prinsip-prinsip tersebut sebagai berikut: pertama dan paling utama yaitu ket- erjangkauan (affordability) biaya untuk memanfaatkan fasilitas pelayanan haruslah relatif murah hal ini terjadi agar masyarakat mampu untuk membayar menjangkaunya (affordable) dan akibatnya dapat memanfaatkan pelayanan yang disediakan. Kedua adalah recoverability, suatu proyek penyediaan fasilitas pelayanan bagi masyarakat pada dasarnya harus dapat membiayai dirinya sendiri (recoverable). Apabila tidak, maka dikuatirkan bahwa pelayanan tersebut tidak akan berkelanjutan karena. tidak dapat bertahan menghidupi dirinya sendiri. Ketiga adalah replicability, adalah rencana penyediaan fasilitas pelayanan perkotaan bagi masyarakat bukanlah suatu kegiatan yang sifatnya hanya berlaku di suatu lokasi tertentu, karena penyediaan tersebut belum tentu dapat diimplementasikan di tempat lain pada waktu yang berbeda. Berarti bahwa kegiatan penyediaan fasilitas pelayanan perkotaan bagi masyarakat bukanlah suatu kegiatan yang sifatnya proyek, tetapi lebih kepada program, artinya direncanakan untuk dapat dilaksanakan di tempat lain yang membutuhkan (replicable).

Penyediaan fasilitas pelayanan perkotaan (fasilitas sosial, ekonomi dan pemerintahan) haruslah memenuhi ketiga prinsip diatas, hal ini dimaksudkan agar pembangunan yang dapat memenuhi prinsipprinsip tersebut maka pelayanan perkotaan dapat dimanfaatkan oleh masyarakat banyak, dan dapat berlangsung secara berkelanjutan.

Menurut Wikarta (2004: 101), manfaat yang didapatkan dari adanya pengembangan pusat-pusat pertumbuhan ini jika dihubungkan dengan data BPS menunjukan bahwa (a) kontribusi daerah perkotaaan terhadap pendapatan regional dan nasional pada tahun 1997 mencapai $40 \%$ dan pada tahun 2000 mencapai $60 \%$. (b) meningkatkan penyerapan tenaga kerja dalam jumlah besar baik itu dari daerah perkotaan dan bagi daerah pedesaan yang termasuk daerah hinterlandnya (c) sumber inovasi pembangunan (d) pusat pelayanan ekonomi, meliputi pemerintahan, pendidikan, kesehatan dan perdagangan bagi penduduk. Hal inilah, yang menyebabkan 


\section{Elastisitas - Jurnal Ekonomi Pembangunan \\ Vol. 2 No. 1, Maret 2020}

pengembangan perkotaan di Indonesia mempunyai peran yang besar dalam pertumbuhan ekonomi wilayah.

\section{METODE PENELITIAN}

Jenis penelitian yang digunakan adalah penelitian deskriptif, yaitu suatu metode dalam meneliti status kelompok manusia, suatu objek, suatu kondisi, suatu system pemikiran ataupun suatu peristiwa pada masa sekarang guna membuat diskripsi, gambaran atau lukisan secara sistimatis, factual dan akurat mengenai fakta-fakta serta hubungan antara yang diselidiki, dianalisis kemudian disimpulkan. (Nazir, 1999: 63).

Lokasi Penelitian dilakukan di Pulau Lombok, yang terdiri atas 5 kabupaten/kota.

Mengumpulan data dilakukan adalah metode kasus (case study) dengan tehnik pengumpulan data yang digunakan adalah:

Studi Kepustakaan dan dokumentasi. Jenisdata yang digunakan dalam penelitian ini adalah data kuantatif berupa data sekunder. Data tersebut adalah data PDRB secara sektoral, Jumlah Penduduk, PDRB per kapita dan jarak antara kota Mataram dengan kabupaten yang ada di Pulau Lombok data nilai tambah setiap sector.

Analisis Statis location quotient (SLQ) ini adalah sebagai berikut:

Formula Metode analisis yang digunakan adalah metode Sintesis Analisis SLQ dan DLQ.

Rumus dari Statis Location Quotient
(SLQ):

$\mathrm{S} \mathrm{LQ} i=\frac{\frac{V_{i j}}{V_{i}}}{\frac{V_{i n}}{V_{n}}}$

Dimana:

SLQ = Location Quotient di Kabupaten Kota i di Pulau Lombok

$v i j=$ PDRB sektor $\mathrm{i}$ pada Kabupaten/Kota i yang di Pulau Lombok

$v i=$ PDRB di Kabupaten/kota i di Pulau Lombok

$V i$ n $=$ PDRB sektor i di Provinsi NTB
$V n=$ PDRB Provinsi NTB

Dengan menggunakan kriteria pengukuran yang dikemukakan oleh BandavidVal (1991: 74) maka setelah dihitung nilai SLQ tersebut mengandung pengertian sebagai berikut:

a. Jika LQ $>1$ menunjukkan sektor ke-i pada Kabupaten dan Kota di Pulau Lombok tergolong sektor basis, atau sektor $\mathrm{i}$ di Kabupaten /Kota di Pulau Lombok lebih spesialis dari pada sektor yang sama di Provinsi NTB.

b. Jika SLQ $<1$ menunjukkan sektor ke-i pada Kabupaten/Kota di Pulau Lombok tergolong sektor non basis, atau sektor i di Kabupaten/Kota di Pulau Lombok kurang spesialis dari pada sektor yang sama di Provinsi NTB

c. Jika $\mathrm{SLQ}=1$ menunjukkan keswasembadaan (self-sufficiency) sektor i pada di Kabupaten/Kota, atau sektor i di Kabupaten/Kota memiliki spesialis yang sama dengan sektor yang sama di Provinsi NTB

Metode SLQ tersebut mempunyai keterbatasan karena besifat statis dan hanya digunakan untuk mengestimasi perubahan sector unggulan pada tahun tertentu saja. Untuk mengatasi keterbatasan metode LQ statis, maka akan digunakan metode LQ Dinamis (DLQ) yang mampu mengakomodasi perubahan struktur ekonomi wilayah dalam kurun waktu tertentu. Menurut Saharuddin (2006) DLQ memasukan laju pertumbuhan rata-rata terhadap masing-masing nilai tambah sektoral maupun PDRB untuk kurun waktu antara 0 sampai tahun t. Bentuk persamaan matematis DLQ adalah dengan formula sebagai berikut:

$$
\mathrm{DLQij}=\left[\frac{\frac{(1+g i j)}{(1+g j)}}{\frac{(1+G j)}{(1+G)}}\right]=\frac{I P P S i j}{I P P S i}
$$

Dimana:

IPPSij = Indeks potensi perkembangan sector I didaerah $\mathrm{J}$

IPPSi $=$ Indeks potensi perkembangan sector I di wilayah referensi

Gij = Laju pertumbuhan sector I di daerah $\mathrm{j}$ 


\section{Elastisitas - Jurnal Ekonomi Pembangunan \\ Vol. 2 No. 1, Maret 2020}

$\mathrm{Gi}=$ Laju pertumbuhan sector I di wilayah referensi

$\mathrm{Gi}=$ Rata-rata laju pertumbuhan di daerah $\mathrm{J}$

$\mathrm{Gi}=$ Rata-rata laju pertumbuhan di wilayah referensi

Jika DLQ = 1 berarti laju pertumbuhan sector I terhadap laju pertumbuhan PDRB didaerah $(\mathrm{J})$ sebanding dengan laju pertumbuhan sector tersebut dalam PDRB wilayah referensi. Jika DLQ $<1$ berarti proporsi laju pertumbuhan sector I terhadap laju pertumbuhan PDRB daerah $\mathrm{J}$ lebih rendah dibandingkan proporsi laju sector tersebut terhadap PDRB wilayah wilayah referensi. Sebaliknya jika DLQ $>1$ bararti proporsi laju pertumbuhan sector I terhadap PDRB daerah $\mathrm{J}$ lebih cepat dibandingkan dengan proporsi laju pertumbuhan sector tersebut terhadap PDRB wilayah Selanjutnya klasifikasi sector berdasarkan nilai SLQ dan DLQ pada setiap Kabupaten/ Kota di Pulau Lombok dapat dilakukan seperti pada tabel berikut:

\begin{tabular}{|l|l|l|}
\hline KRITERIA & \multicolumn{1}{|c|}{ SLQ $>\mathbf{1}$} & \multicolumn{1}{c|}{ SLQ $<\mathbf{1}$} \\
\hline DLQ $>1$ & Sektor Unggulan & Sektor andalan \\
\hline DLQ $<1$ & Sektor Prospektif & Sektor tertinggal \\
\hline
\end{tabular}

Keterangan:

Berdasarkan matriks di atas dapat diketahui bahwa sector unggulan dengan syarat DLQ $>$ 1 dan LQ $>1$, merupakan sector pada saat ini merupakan sector unggulan dan tetap unggul pada beberapa tahun ke depan. Untuk sector andalan dengan syarat DLQ $>1$ dan LQ $<1$ merupakan sector yang saat ini belum unggul tetapi dalam beberapa waktu ke depan berpotensi unggul. Untuk sector prospektif dengan syarat LQ $>1$ dan DLQ $<1$ sektor yg pada saat ini unggul tetapi tidak berpotensi unggul pada beberapa tahun ke depan, sedangkan sector tertinggal dengan syarat LQ $<1$ dan DLQ $<1$ dinyatakan tidak unggul untuk saat ini dan pada beberapa waktu ke depanpum belum berpotensi untuk menjadi sector unggul.

\section{Analisis Keterkaitan Wilayah (Gravitasi)}

Analisis ini digunakan untuk mengetahui interaksi antar daerah, dimana tolok ukur dari metode ini adalah jarak antar daerah dengan jumlah penduduk masing-masing daerah yang diteliti.

Model matematiknya Suwarjoko dalam Wiyadi dan Rina 2002 Sadalah sebagai berikut:

$$
\mathrm{I}_{12}=\mathrm{a}\left(\mathrm{W}_{1} \mathrm{P}_{1}\right)\left(\mathrm{W}_{2} \mathrm{P}_{2}\right) / \mathrm{J}^{\mathrm{b}}{ }_{12}
$$

Keterangan:

$\mathrm{I}_{12}$ : interaksi dalam wilayah 1 dan 2

$\mathrm{W}_{1}$ : PDRB perkapita wilayah 1 (rupiah)

$\mathrm{W}_{2}$ : PDRB perkapita wilayah 2 (rupiah)

$\mathrm{P}_{1}$ : jumlah penduduk wilayah 1

$\mathrm{P}_{2}$ : jumlah penduduk wilayah 2

$\mathrm{J}_{12}$ : jarak antar wilayah 1 dan 2 (meter)

a : Konstanta nilainya 1

b : Konstanta nilainya 2

Nilai I12 menunjukan eratnya hubungan antara wilayah 1 dan wilayah 2 , semakin tinggi nilaiI 12 maka semakin erat hubungan antara dua wilayah, dengan demikian semakin banyak pula perjalanan kegiatan ekonomi atau arus barang dan jasa antara wilayah tersebut seabagai konsekwensi interaksi antar wilayah dalam satu kawasan.

\section{HASIL DAN PEMBAHASAN}

Sektor Ekonomi; Unggulan, Prospektif, Andalan dan sector tertinggal

Kota Mataram sebagai pusat pemerintahan Provinsi Nusa Tenggara Barat, tidak dipungkiri juga sebagai pusat pertumbuhan. Salah satu indikator yang dapat dijadikan petunjuk adalah besaran angka SLQ pada tiga sektor utama, yaitu sektor primer (sektor 1. Pertanian, Kehutanan dan Perikanan, serta sektor 2. Pertambangan dan Penggalian), sektor Sekunder atau Industri (3. Industri Pengolahan; 4. Pengadaan Listrik dan Gas; 5. Pengadaan Air, Pengolahan Sampah, Limbah dan Daur Ulang; 6. Konstruksi) dan sektor Tersier (7. Perdagangan Besar dan Eceran, Reparasi Mobil dan Sepeda Motor; 8. Transportasi dan Pergudangan; 9. Penyediaan Akomodasi dan Makan Minum; 10. Informasi dan Komunikasi; 11. Jasa Keuangan dan Asuransi; 12. Real Estate; 13. Jasa Perus- 


\section{Elastisitas - Jurnal Ekonomi Pembangunan \\ Vol. 2 No. 1, Maret 2020}

ahaan; 14. Administrasi Pemerintaahan, Pertahanan dan Jaminan Sosial Wajib; 15. Jasa Pendidikan; 16. Jasa Kesehatan dan Kegiatan Sosial; 17. Jasa Lainnya).

Kota Mataram bukan lagi sebagai Kota Agraris melainkan Kota Industri/Jasa dan memiliki ciri-ciri sebagai pusat pertumbuhan bagi daerah-daerah sekitarnya.

Tabel: Rata-rata Angka static location Quotient (SLQ)

Kabupaten/Kota di Pulau Lombok Provinsi

Nusa Tenggara Barat,

Kurun waktu 2013 -2017

\begin{tabular}{|r|r|r|r|r|r|}
\hline \multicolumn{1}{|c|}{ SEKTOR } & \multicolumn{1}{|c|}{ KLU } & MATARAM & \multicolumn{1}{c|}{ LOBAR } & LOTENG & LOTIM \\
\hline 1 & 1,68 & 0,18 & 0,79 & 1,23 & 1,07 \\
\hline 2 & 2,03 & 0,00 & 1,95 & 1,46 & 1,68 \\
\hline 3 & 0,48 & 1,94 & 0,89 & 1,36 & 1,64 \\
\hline 4 & 2,19 & 1,32 & 1,04 & 0,96 & 0,89 \\
\hline 5 & 2,23 & 2,10 & 1,15 & 1,63 & 0,78 \\
\hline 6 & 1,46 & 1,01 & 1,18 & 1,38 & 1,01 \\
\hline 7 & 1,67 & 1,34 & 0,85 & 0,91 & 1,00 \\
\hline 8 & 1,24 & 1,33 & 1,18 & 2,03 & 0,54 \\
\hline 9 & 4,91 & 0,73 & 3,19 & 0,63 & 0,42 \\
\hline 10 & 1,49 & 2,97 & 0,92 & 0,81 & 0,76 \\
\hline 11 & 1,42 & 2,62 & 0,77 & 0,70 & 0,62 \\
\hline 12 & 2,24 & 1,42 & 0,94 & 1,25 & 0,95 \\
\hline 13 & 2,34 & 2,20 & 0,55 & 0,91 & 0,55 \\
\hline 14 & 1,11 & 1,24 & 0,93 & 1,09 & 0,98 \\
\hline 15 & 1,93 & 1,55 & 0,93 & 1,10 & 0,94 \\
\hline 16 & 1,33 & 2,20 & 0,85 & 1,34 & 0,92 \\
\hline 17 & 1,63 & 2,09 & 1,00 & 1,14 & 0,81 \\
\hline
\end{tabular}

Sumber: Data BPS di olah.

Tabel di atas menunjukkan bahwa KLU (Kabupaten Lombok Utara), Lombok Tengah dan Lombok Timur memiliki keunggulan di sektor 1 (Pertanian), juga Sektor 2 (Pertambangan dan Penggalian). Ini mengindikasikan bahwa Ke tiga kabupaten tersebut merupakan penyanngga atau penyedia hasil-hasil pertanian bagi Kota Mataram, baik untuk konsumsi langsung maupun untuk keperluan input bagi industri pengolahan makanan di Kota Mataram. Sementara itu Kabupaten Lombok Barat nampaknya tidak lagi memiliki keunggulan di sektor pertanian.

Sektor sekunder, seperti Sektor 6 . (Konstruksi)menunjukkan angka SLQ $>1$ di semua wilayah. Ini menunjukkan bahwa ada perkembangan yang merata di seluruh wilayah. Kota Mataram, sebagai pusat mendapat suplai bahan bangunan dari Kabupaten lain, seperti bahan galian, sebaliknya bahan-bahan bangunan, seperti semen, besi beton, dll, bersumber dari Kota Mataram.
KLU dan Lombok Barat nampak memiliki keunggulan di sektor nomor 9, yaitu sektor Penyediaan Akomodasi dan Makan Minum, dengan angka SLQ yang cukup tinggi. Ini dimungkinkan mengingat KLU dan Lombok Barat memiliki keunggulan di sumberdaya alam. KLU dengan tiga Gili, yaitu Gili Air, Terawangan dan Meno. Lombok Barat dengan Kawasan Senggigi, Sekotong dan beberapa gili di bagian selatan, seperti Gili Gede, Gili Nanggu.

Berdasarkan angka DLQ tampak semua Kabupaten/Kota di Pulau Lombok tidak lagi memiliki keunggulan relatif di Sektor Primer, dibandingkan Kabupaten lainnya di Provinsi Nusa Tenggara Barat, di mana angka $\mathrm{DLQ}<1$. Ini menunjukkan bahwa selama kurun waktu empat tahun, 2010-2014, telah terjadiperubahan struktur ekonomi di semua kabupaten di Pulau Lombok, walaupun di beberapa sektor sekunder dan tersier ada angkaangka DLQ 


\section{Elastisitas - Jurnal Ekonomi Pembangunan \\ Vol. 2 No. 1, Maret 2020}

Tabel : Rata-rata Angka Dynamic location Quotient (DLQ)
Kabupaten/Kota di Pulau Lombok Provinsi

Nusa Tenggara Barat,

Kurun waktu 2013 -2017.

\begin{tabular}{|r|r|r|r|r|r|}
\hline \multicolumn{1}{|c|}{ SEKTOR } & \multicolumn{1}{c|}{ KLU } & \multicolumn{1}{c|}{ MATARAM } & \multicolumn{1}{c|}{ LOBAR } & \multicolumn{1}{c|}{ LOTENG } & \multicolumn{1}{c|}{ LOTIM } \\
\hline 1 & 0,99892 & 0,96448 & 0,97186 & 0,86195 & 0,98671 \\
\hline 2 & 0,93049 & 0,64983 & 0,95283 & 0,86433 & 0,98923 \\
\hline 3 & 1,04931 & 1,08351 & 1,01297 & 0,83885 & 1,00069 \\
\hline 4 & 1,00610 & 0,98545 & 1,00296 & 0,84184 & 0,96702 \\
\hline 5 & 1,13029 & 1,14088 & 1,01224 & 0,89321 & 0,96366 \\
\hline 6 & 1,05376 & 1,16468 & 1,03041 & 0,87649 & 1,03095 \\
\hline 7 & 0,98226 & 1,15881 & 0,98813 & 0,88288 & 1,03948 \\
\hline 8 & 0,97007 & 0,32787 & 0,98412 & 4,80187 & 0,99219 \\
\hline 9 & 1,03199 & 1,13875 & 1,01391 & 0,87898 & 0,96739 \\
\hline 10 & 0,97127 & 1,06580 & 1,00992 & 0,89509 & 0,98789 \\
\hline 11 & 0,85346 & 1,15871 & 0,99786 & 0,81014 & 1,00844 \\
\hline 12 & 0,96234 & 1,15920 & 0,98513 & 0,87432 & 0,99067 \\
\hline 13 & 0,94123 & 1,13868 & 0,94372 & 0,83466 & 0,98198 \\
\hline 14 & 1,08748 & 1,06771 & 1,02683 & 0,86617 & 1,05789 \\
\hline 15 & 1,02463 & 1,17512 & 0,99707 & 0,79459 & 0,99730 \\
\hline 16 & 1,04862 & 1,12002 & 0,99813 & 0,87317 & 1,02566 \\
\hline 17 & 1,02341 & 1,13585 & 0,96715 & 0,85527 & 0,99345 \\
\hline
\end{tabular}

Sumber: Data BPS di olah.

Angka DLQ yang tampak menonjol adalah angka DLQ sektor 8 (Transportasi dan Pergudangan) dengan angka DLQ sebesar 4,80187. Menonjolnya angka ini terkait dengan keberadaan Bandara Udara Internasional Lomok dan merupakan sektor yang akan menjadi penggerak perekonommian $\mathrm{Ka}-$ bupaten Lombok Tengah.Sementara berpindahnya Bandara ke Kabupaten Lombok Tengah yang semula di Kota Mataram, berdampak pada angka DLQ sektor 8 di kota Mataram sebesar 0,32787. Ini berarti KotaMataram tidak lagi bertumpu pada sektor Transportasi dan Pergudangan.

Gabungan angka SLQ dan DLQ memberi gambaran sektor-sektor unggulan di suatu wilayah lebih rinci, dalam artian sektorsektor ekonomi dapat diklasifikasikan menjadi sektor unggulan (DLQ dan SLQ $>1$ ), sektor andalan (DLQ $>1$ dan SLQ $<1$ ), sektor prospektik (DLQ $<1$ dan SLQ $>1$ ), serta sektor tertinggal (baik DLQ dan SLQ $<1$ ).

Tabel: Angka SLQ dan DLQ Kabupaten/Kota Se Pulau Lombok

\begin{tabular}{|c|c|c|}
\hline & KLU & SLQ $<1$ \\
\hline & SLQ $>1$ & 3 \\
\hline DLQ $>1$ & $4,5,6,9,14,15,16,17$ & - \\
\hline DLQ $<1$ & $1,2,7,8,10,11,12,13$, & SLQ $<1$ \\
\hline \multicolumn{3}{|c|}{ KOTA MATARAM } \\
\hline SLQ $>1$ & 9 \\
\hline DLQ $>1$ & $3,5,6,7,10,11,12,13,14,15,16,17$ \\
\hline DLQ $<1$ & 4,8 & SLQ $<1$ \\
\hline \multicolumn{2}{|c|}{ LOBAR } & $3,10,14$ \\
\hline DLQ $>1$ & SLQ $>1$ & $1,7,11,12,13,15,16$, \\
\hline DLQ $<1$ & $4,5,6,9$, & SLQ $<1$ \\
\hline
\end{tabular}




\section{Elastisitas - Jurnal Ekonomi Pembangunan \\ Vol. 2 No. 1, Maret 2020}

\begin{tabular}{|c|c|c|}
\hline DLQ $>1$ & 8 & - \\
\hline DLQ $<1$ & $1,2,312,14,16,17$ & $4,7,9,10,11,13$, \\
\hline \multicolumn{3}{|c|}{ LOTIM } \\
\hline DLQ $>1$ & SLQ $>1$ & SLQ $<1$ \\
\hline DLQ $<1$ & $3,6,7$ & 11,16 \\
\hline
\end{tabular}

Sumber: Data BPS diiolah.

Keterangan:

1. Sektor Pertanian, Kehutanan dan Perikanan.

2. Pertambangan dan penggalian.

3. Industri Pengolahan.

4. Pengadaan Listrik dan Gas.

5. Pengadaan Air, Pengadaan sampah, Limbah dan Daur ulang.

6. Kontruksi.

7. Perdagangan besar dan Ecerdan; Reparasi Mobil dan sepeda Motor.

8. Transportasi dan pergudangan.

9. Penyediaan Akomodasi dan Makan Minum.

10. Informasi dan Komunikasi.

11. Jasa Keuangan dan Asuransi.

12. Real Estate.

13. Jasa Perusahaan

14. Administrasi Pemerintahan, Pertahanan dan Jaminan Sosial Wajib.

15. Jasa Pendidikan.

16. Jasa Kesehatan dan Kegiatan Sosial.

17. Jasa Lainnya.

Berdasarkan Tabel di atas tampak bahwa apa yang di deskripsikan pada pembahasan terdahulu konsisten dengan apa yang tampak pada tabel di atas. Kota Mataram unggul hampir di semua sektor sekunder dan tersier, yaitu ada sebanyak 12 sektor unggu- lan, satu sektorandalan dan dua sektor prospektif. KLU sebagai Kabupaten termuda menunjukkan progresifitas yang menonjol, dengan delapan sektor unggulan, satu sektor andalan dan delapan sektor prospektif.

Ada beberapa sektor unggulan di setiap Kabupaten/Kota yang sama, seperti sektor 6 (sektor Konstruksi) terklasifikasi sebagai sektor unggulan di empat kabupaten, kecuali Lombok Tengah. Ini dapat dijadikan indikasi adanya keterkaitan antar sektor dan antar wilayah yang saling memperkuat pengembangan sektor tersebut di setiap wilayah. Kota Mataram sebagai pusat pertumbuhan, dalam pengembangan sektor konstruksi disangga oleh Kabupaten lain, dalam hal penyediaan bahan galian, sementara untuk keperluan bahan-bahan konstruksi hasil industri, seperti semen, besi, dll, disediakan oleh Kota Mataram.

Untuk mengetahui kabupaten yang memiliki interaksi ekonomi yang kuat dengan kota Mataram sebagai pusat pertumbuhan digunakan analisis Model Gravitasi.Tolak ukur dari dari metode ini adalah jarak antar daerah dengan jumlah penduduk masingmasing daerah yang ditiliti.

Tabel Interakri Ekonomi Wilayah Kota MataramdenganKabupaten-kabupatenSekitar di Pulau Lombok Tahun $2013-2017$

\begin{tabular}{|l|l|l|l|l|c|}
\hline $\begin{array}{c}\text { InteraksiEkonomi } \\
\text { Wilayah }\end{array}$ & \multicolumn{1}{|c|}{ Tahun } \\
\cline { 2 - 6 } & $\mathbf{2 0 1 3}$ & \multicolumn{1}{|c|}{$\mathbf{2 0 1 4}$} & $\mathbf{2 0 1 5}$ & $\mathbf{2 0 1 6}$ & $\mathbf{2 0 1 7}$ \\
\hline Mataram - Lotim & $5.38052 \mathrm{E}+34$ & $6.15417 \mathrm{E}+36$ & $2.33169 \mathrm{E}+32$ & $2.65261 \mathrm{E}+32$ & $3.00868 \mathrm{E}+32$ \\
\hline Mataram - Loteng & $3.55082 \mathrm{E}+27$ & $1.30283 \mathrm{E}+28$ & $5.32413 \mathrm{E}+25$ & $6.10571 \mathrm{E}+25$ & $7.01448 \mathrm{E}+25$ \\
\hline Mataram Lobar & $6.33116 \mathrm{E}+27$ & $7.22681 \mathrm{E}+27$ & $2.73395 \mathrm{E}+25$ & $3.10614 \mathrm{E}+25$ & $3.54092 \mathrm{E}+25$ \\
\hline Mataram - KLU & $2.64832 \mathrm{E}+33$ & $3.0514 \mathrm{E}+33$ & $1.1539 \mathrm{E}+31$ & $1.31145 \mathrm{E}+31$ & $1.49898 \mathrm{E}+31$ \\
\hline
\end{tabular}




\section{Elastisitas - Jurnal Ekonomi Pembangunan \\ Vol. 2 No. 1, Maret 2020}

Berdasarkan pada table di atas diketahui bahwainteraksi yang kuat dengan kota Mataram sebagai pusat pertumbuhan ekonomi adalah selama tahun 2010-2011 adalah Kabupaten Lombok Barat dengan Indeks interaksi yang terbesar, dimana Kabupaten ini mempunyai jarak yang terdekat dengan kota mataram yang ditunjang oleh jumlah penduduk yang dan tingkat pendapatan perkapita yang yang tinggi

Pada tahun 2012-2014 posisi interaksi ekonomi yang terkuat beralih ke Kabupaten Lombok Tengah dengan Indeks Interaksi yang terbesar, hal ini ditunjang oleh lancarnya tramsportasi dari Mataram ke Bandara Internasional Lombok (BIL), di samping itu PDRP/Kapita telah meningkat tajam sampai lebih 3 x lipat dari tahun 2010. Sedangkan interaksi ekonomi yang terendah adalah sejak tahun 2010-2014 adalah Kabupaten Lombok Utara (KLU). Hal ini sebabkan karena Kabupaten ini merupakan Kabupaten yang termudah di Pulau Lombok dengan tingkat pendapatan perkapita dan jumlah penduduk yang rendah.

\section{KESIMPULAN DAN SARAN}

\section{a. Kesimpulan} pulkan

Berdasarkan pembahasan dapat disim-

1) Kota Mataram merupakan pusat pertumbuhan bagi pengembangan wilayah Kabupaten se Pulau Lombok;

2) Pertanian dan Pertambangan/penggalian tidak lagi sebagai sektor unggulan hampir di semua Kabupaten/Kota se Pulau Lombok.

3) Sektor sekunder dan tersier merupakan sektor unggulan hampir di semua Kabupaten/Kota se Pulau Lombok;

4) Ada keterkaitan antar sektor dan wilayah Kabupaten/Kota se Pulau Lombok yang saling memperkuat dalam pengembangan sektor dan wilayah.

\section{b. Saran-saran}

1) Mengingat sepanjang tahun penelitian interaksi terkecil berada di dua wilayah yai- tu antara Kota Mataram dengan Kabupaten Lombok Utara, maka secara teori perlu dilakukan penelitian lanjutan yang mengarah pada Breaking Point Theory. Teori tersebut mengajukan konsep titik hentiekonomi dari kedua wilayah. Dalam praktiknya, pemerintah daerah keduanya dapat mengajukan konseptitik kutub pertumbuhan baru yang paling menguntungkan diantara keduanya

2) Pemerintah daerah, dalam rangka perencanaan pembangunan, baik secara sektoral maupun regional, agar memperhatikan sektor-sektor yang menjadi unggulan dan memiliki keterkaitan yang kuat;

3) Perlu dikaji sampai sub sektor atau komoditas unggulan untuk mendapatlkan gambaran yang lebih rinci, sehingga perencanaan pembangunan akan makin tajam dan mencapai tingkat pertmbuhan yang lebih tinggi.

\section{DAFTAR PUSTAKA}

Arsyad, Lincolin, 1992, Ekonomi Pembangunan, STIE YKPN, Yogyakarta.

Azis, Iwan Jaya, 1994, Ilmu Ekonomi Regional dan Beberapa Aplikasinya di Indonesia, Lembaga Penerbit, Fakultas Ekonomi Universitas Indonesia.

Bendavid-Val, Avrom, 1991, Regional and Local Economic Analysis for Practioners, Praeger Publisher, Fourt Edition, New York and London.

Hoover, Edgar M., 1975, An Introduction to Regional Economics, Alfred A. Knopf, NewYork, Second Edition.

Kadariah, 1985, Ekonomi Perencanaan, Lembaga Penerbit, Fakultas Ekonomi UniversitasIndonesia, Jakarta.).

Martono, Pan Budi, 2007. Perencanaan Pengembangan Ekonomi Masyarakat Kabupaten Gorut Badan Perencanaan Daerah Kabupaten Gorontalo. Limboto 
Maulana Yusuf, 1999. Ekonomi dan Keuangan Indonesia (EKI) Volume XLVII No 2

Richardson, H., W., 1977. Dasar-dasar Ilmu Ekonomi Regional, (terjemahan paul Sihotang), Lembaga Penerbitan, FE-UI, Jakarta.

Suryana, 2000. Ekonomi Pembangunan, Problema dan Pendekatan, Penerbit Salemba Empat, Jakarta.

Sjafrizal, 1997. Pertumbuhan Ekonomi Wilayah Indonesia Bagian Barat, Prisma No 3 LP3SJakarta .2008, Ekonomi Regional: Teori dan Aplikasi, Baduose Media, Padang

Tarigan, R. 2004. Ekonomi Regional Teori dan Aplikasi, PT Bumi Aksara, Jakarta.

Widodo, Tri 2006, Perencanaan Pembangunan Aplikasi Komputer Era Otonomi Daerah, Yogyakart 